\title{
Superior GVHD-free, relapse-free survival for G-BM to G-PBSC grafts is associated with higher MDSCs content in allografting for patients with acute leukemia
}

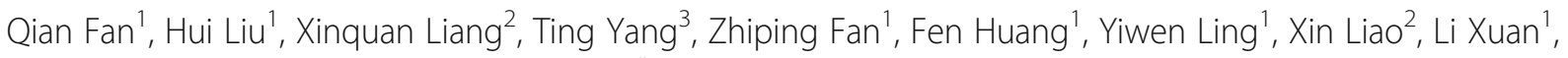

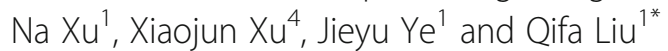

\begin{abstract}
Background: Granulocyte colony-stimulating factor (G-CSF)-mobilized peripheral blood stem cells (G-PBSC) has largely replaced unstimulated bone marrow (un-BM) for allografting because of accelerated engraftment, but with a higher morbidity and mortality of graft-versus-host-disease (GVHD). Recent studies suggested that G-CSF-primed BM (G-BM) had similar engraftment but lower morbidity and mortality of GVHD comparing to G-PBSC. A prospective, randomized, multicenter study was conducted to compare G-BM with G-PBSC as the grafts in allogeneic hematopoietic stem cell transplantation (allo-HSCT) for acute leukemia in first complete remission (CR1).

Methods: Totally 101 adult leukemia in CR1 undergoing HLA-identical sibling transplants were randomized into G-BM or G-PBSC group. The primary study endpoint was GVHD-free/relapse-free survival (GRFS).

Results: Both the engraftment of neutrophil and platelet were 2 days later in G-BM than in G-PBSC group ( $P=0.412$, $P=0.39$ ). G-BM group showed significantly lower II-IV acute GVHD (aGVHD) and similar III-IV aGVHD compared with G-PBSC group (12.2\% vs $28.8 \%$ for II-IV, $P=0.048 ; 4.1 \%$ vs $9.6 \%$ for III-IV aGVHD, $P=0.267$, respectively). The overall cumulative incidence of chronic GVHD (cGVHD) at 3 years were $22.3 \% \pm 6.3 \%$ and $44.8 \% \pm 7.6 \%(P=0.026)$, respectively, and extensive cGHVD were $4.5 \% \pm 3.1 \%$ and $15 \% \pm 5.3 \%(P=0.08)$, respectively, in $\mathrm{G}-\mathrm{BM}$ and $\mathrm{G}$-PBSC groups. Two groups had similar 3-year relapse, transplant-related mortality (TRM), overall survival (OS), and disease-free survival (DFS) (all $P>0.05)$. G-BM group showed significantly higher probability of GRFS than G-PBSC group $(73.5 \% \pm 6.3 \%$ vs $55.8 \% \pm 6.9 \%$ at 1 year, $P=0.049 ; 69.0 \% \pm 6.7 \%$ vs $49.7 \% \pm 7.0 \%$ at 2 and 3 years, $P=0.03$, respectively). Graft content analysis revealed statistically higher frequency of myeloid-derived suppressor cells (MDSCs) in the G-BM than in G-PBSC grafts $(P<0.01)$, and recipients received statistically higher numbers of MDSCs in G-BM than in G-PBSC group $(P=0.045)$. Numbers of MDSCs infused to patients were negatively correlated with the severity of aGVHD $(P=0.032, r=-0.214)$. Multivariate analysis showed that MDSC cell dose below the median $(H R=3.49$, $P<0.001)$, recipient age $(H R=2.02, P=0.039)$, and high risk of disease $(H R=2.14, P=0.018)$ were independent risk factors for GRFS.
\end{abstract}

Conclusions: G-BM grafts lead a better GRFS and less GVHD associated with a higher MDSCs content compared with G-PBSC grafts.

Keywords: Granulocyte colony-stimulating factor (G-CSF)-primed bone marrow, Graft-versus-host disease, GVHD-free/ relapse-free survival, Myeloid-derived suppressor cells

\footnotetext{
*Correspondence: liuqifa628@163.com

'Department of Hematology, Nanfang Hospital, Southern Medical University,

No. 1838 North Guangzhou Avenue, Guangzhou 510515, China

Full list of author information is available at the end of the article
} 


\section{Background}

Granulocyte colony-stimulating factor (G-CSF)-mobilized peripheral blood stem cells (G-PBSC) has replaced bone marrow (BM) as the most commonly used source of hematopoietic stem cells (HSCs) because of faster engraftment and practicability as well as acceptable graftversus-host disease (GVHD) [1]. Even though, some studies suggested that G-PBSC transplants might result in a higher morbidity and mortality of GVHD, especially chronic GVHD (cGVHD), compared with unstimulated BM transplants, as G-PBSC grafts contain 4- to 10-fold more T lymphocytes [2, 3]. Recently, several prospective and retrospective studies suggested that G-CSF-primed BM (G-BM) grafts had similar engraftment but lower morbidity and mortality of GVHD compared with G-PBSC grafts [4].

The mechanisms of G-CSF-primed grafts inducing immune tolerance are extensively studied, which include the induction of $\mathrm{T}$ helper type 2 (Th2) cell polarization and increase of $\mathrm{CD} 4{ }^{+} \mathrm{CD} 25^{+}$regulatory $\mathrm{T}$ (Treg) cells and tolerogenic dendritic cell differentiation [5-8]. But, these mainly focused on PBSC grafts. The mechanisms of G-BM grafts inducing immune tolerance are not fully understood and whether G-CSF has similar impact on $\mathrm{BM}$ or other mechanisms exist in G-BM associated immune tolerance was rarely studied.

Each graft source has its unique compositions, such as the number of CD34 ${ }^{+}$cells, different $\mathrm{T}$ cell subtypes and natural killer (NK) cells and, possibly, other cellular as well as cytokine components, which affect the time frame of engraftment and incidence of GVHD [9, 10]. Myeloid-derived suppressor cells (MDSCs) are a heterogeneous population of myeloid progenitors and immature myeloid cells (IMC) with a potent immunosuppressive activity, which establish an important role in the tumor immune responses $[11,12]$. Recently, a few studies began to focus on the role of MDSCs in the graft immune tolerance. In animal model, Highfill et al. reported that cotransplantation of MDSCs might decrease the severity and mortality of aGVHD [13]. In human, Vendramin et al. documented that the numbers of MDSCs in the grafts were negatively correlated with incidence of aGVHD [14]. Our previous study showed that G-CSF might induce the expansion of MDSCs in the BM and peripheral blood (PB) in vivo and higher frequency of MDSCs consisted in G-BM grafts than G-PBSC grafts [15].

Based on these study results, we hypothesized that GBM grafts lead a better GVHD-free/relapse-free survival (GRFS) and less GVHD associated with a higher MDSC content compared with G-PBSC grafts except for T cells and other compositions. And MDSCs might play the immunoregulatory role in GVHD. To identify this hypothesis, a randomized multicenter clinical trial was conducted.

\section{Methods}

\section{Study design and patients accrual}

This prospective, randomized, open-label study was conducted from February 2013 to April 2015 in Nanfang Hospital, Southern Medical University, the First People's Hospital of Chenzhou, People's Hospital of Zhongshan City, and Concord Hospital of the Fujian Medical University. One hundred one patients with acute leukemia in first complete remission (CR1) undergoing allogeneic stem cell transplantation from an HLA-identical sibling were enrolled in this trial of G-BM or G-PBSC as the source of stem cells. The study was performed in accordance with modified Helsinki Declaration, and the protocol was approved by respective ethical review boards before study initiation. All patients and donors provided written informed consent.

\section{Conditioning regimen and GVHD prophylaxis}

As we described previously [16], two myeloablative conditioning regimens were used, including $\mathrm{BuCy}$ (busulfan + cyclophosphamide) and TBI (total body irradiation) + Cy. Generally, acute myeloid leukemia (AML) received BuCy and acute lymphoid leukemia (ALL) TBI + Cy. Cyclosporine and short-course methotrexate were given as GVHD prophylaxis [16].

\section{Supportive therapy and infection prophylaxis}

As described previously [16], low molecular weight heparin and prostaglandin $\mathrm{E}$ were used from the beginning of the conditioning to engraftment for hepatic venoocclusive disease (HVOD) prophylaxis. Phenytoin orally was used for the prophylaxis of busulfan toxicities on the central nervous system. Oral sulfamethoxazole were used for prophylaxis of Pneumocystis carinii. Acyclovir and ganciclovir were given for prophylaxis and treatment of cytomegalovirus (CMV) infection as prescribed in previous literature [16]. Antifungal agents were administered according to the history of invasive fungal infection (IFI) or not. Generally, all patients received granulocyte colony-stimulating factor (G-CSF, $5 \mu \mathrm{g} / \mathrm{kg}$ / day) from +3 days post-transplantation until achievement of the peripheral white blood cells count reached $1.0 \times 10^{9} / \mathrm{L}$ or absolute neutrophil count (ANC) reached $0.5 \times 10^{6} /$ L. Patients received red blood cells and platelet transfusions if hemoglobin levels were $\leq 70 \mathrm{~g} / \mathrm{L}$ and platelet count $\leq 20.0 \times 10^{9} / \mathrm{L}$.

\section{Stem cell mobilization and collections}

All donors received G-CSF (filgrastim, Kirin Brewery Co, Tokyo, Japan) $5 \mu \mathrm{g} / \mathrm{kg} /$ day for 5 days. G-BM harvest was performed on the fifth day (volume, $15-20 \mathrm{~mL} / \mathrm{kg}$ patient adjusted ideal weight). At least $3.0 \times 10^{8}$ total nucleated cells $/ \mathrm{kg}$ or $2 \times 10^{6} \mathrm{CD}^{+} 4^{+}$cells $/ \mathrm{kg}$ recipient ideal body weight was collected. G-PBSC harvest was 
performed from day 5 of G-CSF to obtain $6.0 \times 10^{8}$ total nucleated cells $/ \mathrm{kg}$ or a minimum $\mathrm{CD} 34^{+}$cell count of $3 \times 10^{6} / \mathrm{kg}$ recipient ideal body weight.

\section{Flow cytometry analysis in grafts}

Two grafts were analyzed in terms of $\mathrm{CD} 34^{+}$cells, $\mathrm{CD}^{+} \mathrm{T}$ cells and subpopulation $\left(\mathrm{CD}^{+}{ }^{+} \mathrm{CD} 4^{+}, \mathrm{CD}^{+}{ }^{+} \mathrm{CD} 4^{+} \mathrm{CD} 45 \mathrm{RA}^{+}\right.$, $\mathrm{CD}^{+}{ }^{+} \mathrm{CD} 4^{+} \mathrm{CD} 45 \mathrm{RO}^{+}, \mathrm{CD}_{3}{ }^{+} \mathrm{CD} 8^{+}, \mathrm{CD}^{+} \mathrm{CD}^{+} \mathrm{CD}_{4} 5 \mathrm{RA}^{+}$, $\mathrm{CD}^{+}{ }^{+} \mathrm{CD} 25^{+} \mathrm{FOXP3}^{+}$Treg cells), CD19 ${ }^{+} \mathrm{B}$ cells, $\mathrm{CD}^{-} \mathrm{CD}^{-} 6^{+}$ NK cells, and MDSCs by flow cytometry using standard procedures. MDSCs were defined as Lin $^{\text {low/neg }}{ }^{\text {HLA-DR }}$ ${ }^{-} \mathrm{CD}_{3}{ }^{+} \mathrm{CD}_{11 \mathrm{~b}}{ }^{+}$. All results were assayed by BD FACSCanto TMII (BD Biosciences), and the acquired data were further analyzed using BD-FACSDiva Software. Flow cytometric results were represented as percentage positive.

\section{MDSCs suppression assay}

Purified $\mathrm{CD}^{+}$lymphocytes and MDSCs were isolated from G-BM or G-PBSC grafts by CD3 and HLA-DR, CD33 microbeads (Milenyi Biotec, Bergisch Gladbach, Germany), according to manufacturer's instructions. Purity of the selected populations was evaluated by flow cytometry, demonstrating an efficiency of separation above $95 \%$ in all experiments. Purified $\mathrm{CD}^{+} \mathrm{T}$ lymphocytes were labeled with $5 \mu \mathrm{M} 5$, 6-carboxy-fluorescein diacetate succinimidyl ester (CFSE) (Biolegend) and thereafter were co-cultured with isolated MDSCs at a MDSCs-to-CD3 ${ }^{+} \mathrm{T}$ cell ratio of 1:1 and 1:5 in the presence of anti-CD2/CD3/ CD28 biotin beads (Miltenyi Biotec) in RPMI 1640 (Sigma-Aldrich) supplemented with 10\% FBS, penicillin/streptomycin, and $2 \mathrm{mM}$ L-glutamine. For positive control, lymphocytes were stimulated in the absence of MDSCs; for negative control, $\mathrm{CD}^{+}$cells and MDSCs were incubated without the stimuli. After 4 days of culture, the cells were harvested for CFSE dilution analysis by flow cytometry.

\section{Endpoints and definitions}

The primary study endpoint was GRFS. Secondary study endpoints were hematopoietic engraftment, acute and chronic GVHD, early infections, disease relapse, transplantrelated mortality (TRM), overall survival (OS), and diseasefree survival (DFS). GRFS was defined as absence of grade III-IV aGVHD, systemic immunosuppressive therapy requiring cGVHD, relapse, or death for any causes after allogeneic hematopoietic stem cell transplantation (allo-HSCT) [17, 18]. Hematopoietic engraftment was defined as the first of two consecutive days with an absolute neutrophil count in the peripheral blood exceeding $0.5 \times 10^{9} / \mathrm{L}$ and the first of 3 days with an absolute platelet count exceeding $20 \times 10^{9} / \mathrm{L}$ without transfusion support. Complete chimerism was defined as $>95 \%$ donor cells detected. aGVHD was graded according to standard criteria [19], and cGVHD was assessed in patients surviving for more than 100 days post-transplantation and defined as limited or extensive [20]. Relapse was defined by molecular, cytogenetic, or morphologic evidence of the original hematologic disease in the peripheral blood, BM, or any extramedullary site. TRM was defined as death from any cause other than relapse. DFS was defined as survival in a state of continuous complete remission.

\section{Statistical analysis}

Analysis was performed on October 31, 2016. Comparisons of categorical variables were made by means of chi-squared and Fisher's exact tests for small numbers. Differences between numerical variables were calculated by means of the Mann-Whitney $U$ test. Numerical variables were analyzed as categories based on their values being below or above the median of the entire cohort. Correlation analysis between categorical variables was calculated using Spearman's correlation test. Incidence of time-dependent outcomes was estimated by the method of Kaplan-Meier and compared by the log-rank test. Cumulative incidence curves in a competing risks setting were used to calculate probabilities of relapse and TRM. Cumulative incidence of relapse were calculated by regarding death as the competing event, whereas estimates of TRM were calculated by regarding disease relapse as the competing event [21]. Gray test was used to compare the incidence of TRM and relapse between groups $[22,23]$. Cox proportional hazards model was used to evaluate the associations of patient and graft characteristics with various outcomes. Factors that were tested in the multivariable analyses were patient's age, gender, the source of grafts, primary disease, risk classification, $\mathrm{CD}^{+} \mathrm{T}$ cell dose, Treg cell dose, and MDSC dose. All statistical tests were two-sided, and a $P$ value less than 0.05 was used to indicate statistical significance.

\section{Results}

\section{Patients and transplant characteristics}

A total of 101 patients were enrolled, with 49 randomized to G-BM and 52 to G-PBSC group. The primary diseases included acute myelogenous leukemia (AML, $n=65)$ and acute lymphoblastic leukemia (ALL, $n=36$ ). Patients were all in CR1 and received grafts from matched siblings. The characteristics of patients, donors, and transplants are summarized in Table 1 . There were no significant differences in patients' age, gender, primary disease, and conditioning regimen between the two groups (Table 1 , all $P>0.05)$. G-PBSC recipients received statistically higher numbers of total nucleated cells (TNC), CD34 ${ }^{+}$ cells, and about 4-fold more $\mathrm{CD}^{+}{ }^{+} \mathrm{T}$ cells per kilogram than G-BM recipients (Table 1 , all $P<0.01$ ). 
Table 1 Patient, donor, and transplant characteristics

\begin{tabular}{llll}
\hline & G-BM $(n=49)$ & G-PBSC $(n=52)$ & $P$ value \\
\hline Patient age, median(range), year & $30(13-59)$ & $33(16-48)$ & $28(53.8)$ \\
Male patients (\%) & $24(48.9)$ & & NS \\
Underlying diseases (\%) & & $34(65.4)$ & NS \\
AML & $34(69.4)$ & $18(34.6)$ & \\
ALL & $15(30.6)$ & $27(51.9)$ & NS \\
Risk classification (\%) & & $25(48.1)$ & NS \\
Standard risk & $26(53.1)$ & $38(17-55)$ & NS \\
High risk & $23(46.9)$ & $28(53.8)$ & $18(34.6)$ \\
Donor age, median(range), year & $34(10-20)$ & $8.7(7.2-12.5)$ & NS \\
Male donors (\%) & $25(51.0)$ & $5.6(3.5-12.3)$ & NS \\
Female to male (\%) & $16(32.6)$ & $285.8(68-467)$ & $P<0.01$ \\
Median TNC, $10^{8} / \mathrm{kg}$ (range) & $5.8(3.8-8.2)$ & $3.6(2.3-10.0)$ & $P<0.01$ \\
Median CD34 ${ }^{+}$cell count, $10^{6} / \mathrm{kg}$ (range) & $69.6(22-156)$ &
\end{tabular}

ALL acute lymphoblastic leukemia, $A M L$ acute myelogenous leukemia, $T N C$ total nucleated cells

\section{G-CSF induces an expansion of MDSCs in vivo}

To identify whether G-CSF induces the expansion of MDSCs in vivo, 20 donors were studied for the frequencies of MDSCs in the BM and PB before and after G-CSF mobilization (day 5). MDSCs were quantified with the following gating strategy (Fig. 1a). The results showed, before G-CSF mobilization, the frequencies of MDSCs in the BM and $\mathrm{PB}$ were $0.33 \% \pm 0.15 \%$ and $0.30 \% \pm 0.13 \%$ of total nucleated cells, respectively (Fig. $1 \mathrm{~b}, P=0.32$ ). After 5 days mobilization, the frequency of MDSCs in the BM increased to $0.65 \% \pm 0.29 \%$, compared with $0.41 \% \pm 0.17 \%$ in the G-PB (Fig. 1b, $P<0.01$ ). Both in the BM and PB, the frequencies of MDSCs significantly increased after G-CSF treatment (Fig. 1b, both $P<0.05$ ).

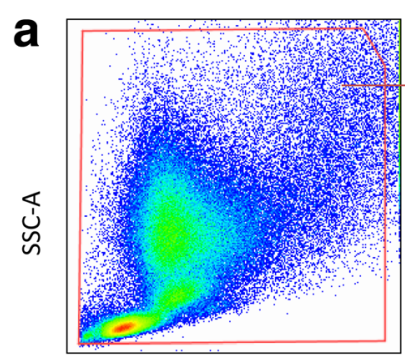

FSC-A

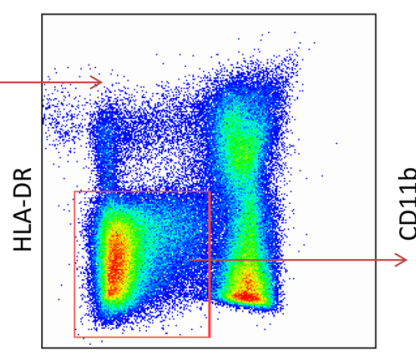

Lin

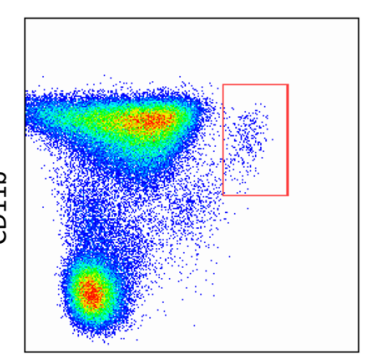

$\mathrm{CD} 33$

b

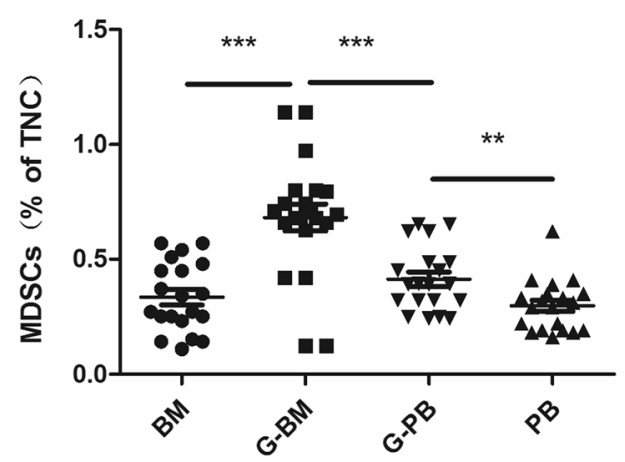

Fig. 1 Expression of MDSCs in the BM and PB before and after G-CSF mobilization. a Sequential gating strategy for MDSC identification (Lin $\left.{ }^{\text {low }}{ }^{\text {neg } H L A-D R}{ }^{-} \mathrm{CD} 11 \mathrm{~b}^{+} \mathrm{CD} 33^{+}\right)$using flow cytometry. b Cumulative dot plots showing MDSC frequencies from BM and PB of 20 donors before and after G-CSF mobilization (**P<0.01, ${ }^{* * *} P<0.001$ ) 


\section{Immunosuppressive activity of MDSCs}

To verify whether G-CSF inducing MDSCs could be defined as functional MDSCs, we determined their immunosuppressive activity. Highly purified MDSCs from G-BM and G-PBSC grafts were, respectively, co-cultured with autologous CFSE-labeled $\mathrm{CD}^{+} \mathrm{T}$ cells for 4 days in the presence of $\mathrm{T}$ cell stimulators. The results showed that there was a significant inhibition of $\mathrm{T}$ cell proliferation in co-culture with MDSCs from the two grafts, which indicated that MDSCs from both G-BM and G-PBSC grafts were immunosuppressive (Fig. 2a, b). Further analysis revealed that the immunosuppressive activity of MDSCs was similar in the two grafts (Fig. $2 \mathrm{~b}, P=0.67$ ).

\section{Graft content analysis}

The percentage and absolute numbers of MDSCs, Treg cells and $\mathrm{CD}^{+} \mathrm{T}$ cells and subsets, $\mathrm{CD} 19^{+} \mathrm{B}$ cells, and $\mathrm{CD}^{-}{ }^{-} \mathrm{CD} 56^{+} \mathrm{NK}$ cells in the grafts for all the donors (49 in G-BM; 52 in G-PBSC group) were summarized in Table 2. As a result, the percentage of $\mathrm{CD}^{+} \mathrm{T}$ cells among lymphocytes was significantly lower in the G-BM than that in the G-PBSC grafts $(P=0.007)$. And the frequency of MDSCs was statistically higher in the G-BM than in the G-PBSC grafts $(0.66 \% \pm 0.23 \%$ vs $0.40 \% \pm 0.19 \%$ of total nucleated cells, respectively, $P<0.01$ ). The percentage of Treg cells in the G-BM was also higher than in the G-PBSC though without statistical significance $(P=0.192)$. The percentage of other cell subsets in the two groups did not differ significantly (all $P>0.05$ ). The absolute numbers of MDSCs infused in the G-BM group was 1.38-7.31 $\times$ $10^{6} / \mathrm{kg}$ (median, 3.93) compared with $1.65-5.98 \times 10^{6} / \mathrm{kg}$ (median, 3.53) in the G-PBSC group $(P=0.045)$. Cell doses of other compositions including $\mathrm{CD}^{+} \mathrm{T}$ cells were all significantly lower in the G-BM than in the G-PBSC group, which were partly associated with significantly less TNC infusion in G-BM than in G-PBSC group.

\section{Engraftment}

Analyses of chimerism revealed that all patients obtained full donor chimerism by day +30 post-transplantation. Median time to neutrophil reconstruction was 14 days (range, 8-23 days) and 12 days (range, 8-19 days), respectively $(P=0.412)$, in the G-BM and G-PBSC groups. Median time to platelet reconstruction was 15 days (range, 9-87 days) and 13 days (range, $9-30$ days), respectively $(P=0.390)$, in the G-BM and G-PBSC groups. To compare with unstimulated $\mathrm{BM}$, the historical data of 32 patients who underwent unstimulated BM transplantation in our institutions between 1997 and 2003 was analyzed. The results showed that both the neutrophil and platelet reconstruction were significantly faster in the G-BM and G-PBSC than those in the unstimulated BM (G-BM, $P=0.023, P=0.014$, respectively; G-PBSC, $P=0.019, P=0.009$, respectively) with a median time of 22 days (range,16-36 days) to neutrophil reconstruction and 27 days (range, 18-46 days) to platelet reconstruction in unstimulated BM group.
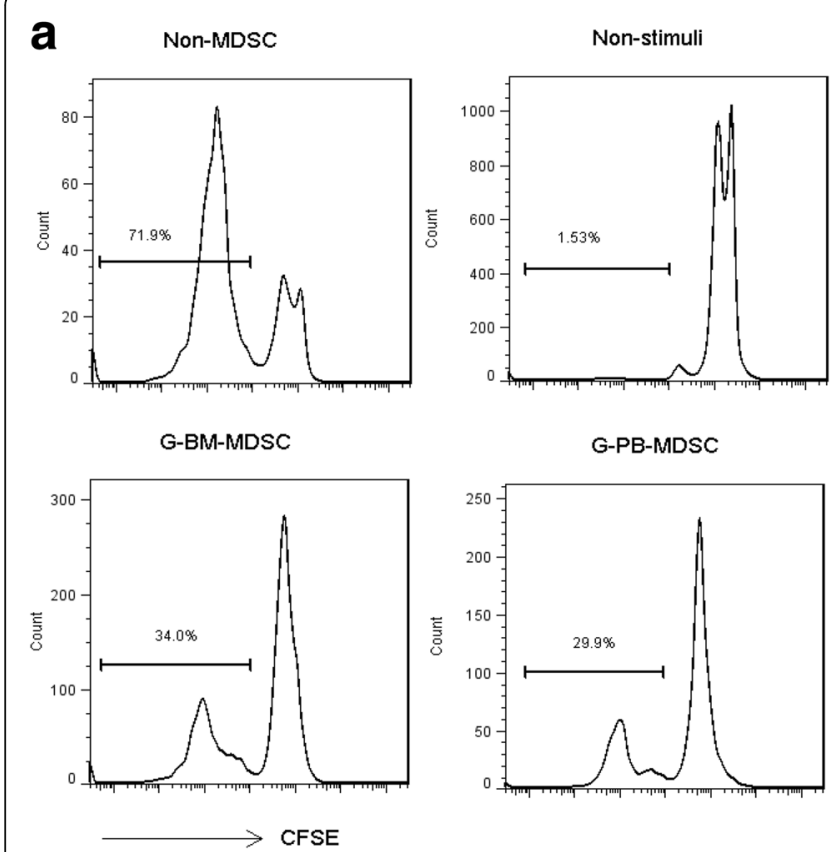

b

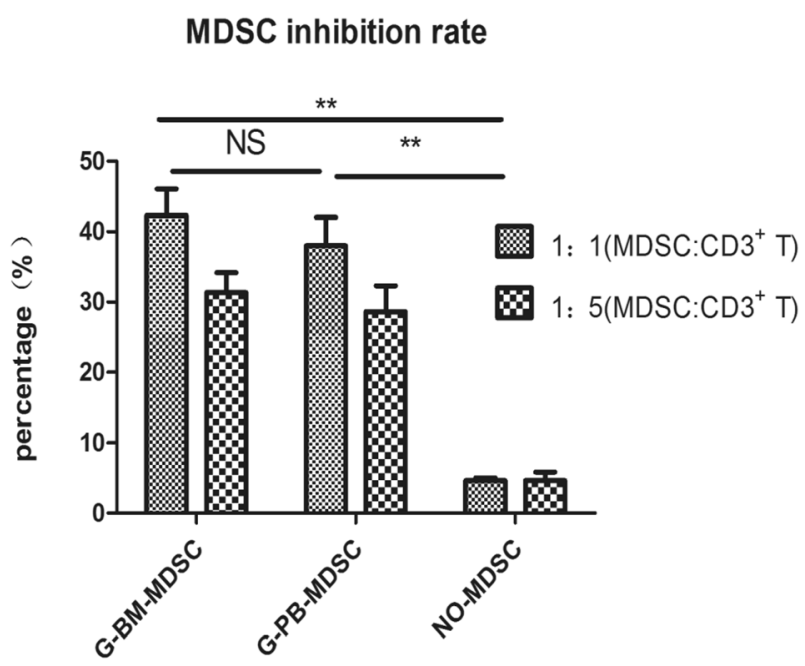

Fig. 2 Suppressive activity of MDSCs isolated from G-BM and G-PBSC grafts. a The proliferation of purified and CFSE-labled CD3+ T cells in the coculture with isolated MDSCs or not. b The inhibition rate of the proliferation of CD3+ T cells by MDSCs. Isolated MDSCs were added at a 1:1 and 1:5 ratio to purified CD3+ T cells in the presence of anti-CD2/CD3/CD28 biotin beads according to manufacturer instructions (Miltenyi Biotec). Data are representative of three independent experiments (NS $P>0.05,{ }^{* *} P<0.01$ ) 
Table 2 G-BM and G-PBSC graft cell subset frequencies and cell doses

\begin{tabular}{|c|c|c|c|c|c|c|}
\hline & \multicolumn{2}{|c|}{$\begin{array}{l}\text { Frequencies of graft cell subsets, (\%), } \\
\text { mean } \pm \text { SD }\end{array}$} & \multirow[b]{2}{*}{$P$} & \multicolumn{2}{|c|}{$\begin{array}{l}\text { Doses of graft cell subsets infused, } 10^{6} \text { cells } / \mathrm{kg} \text { of body weight, } \\
\text { median (min-max) }\end{array}$} & \multirow[b]{2}{*}{$P$} \\
\hline & G-BM $(n=49)$ & G-PBSC $(n=52)$ & & G-BM $(n=49)$ & G-PBSC $(n=52)$ & \\
\hline $\mathrm{CD}^{+}$ & $60 \pm 10$ & $68.0 \pm 14.0$ & 0.007 & 69.6(22-156) & $285.8(68-467)$ & $<0.001$ \\
\hline $\mathrm{CD}^{+}{ }^{+} \mathrm{CD} 4^{+}$ & $29 \pm 8.7$ & $35.0 \pm 10.7$ & 0.065 & $33(10-56)$ & $139.3(45-257)$ & $<0.001$ \\
\hline $\mathrm{CD}^{+}{ }^{+} \mathrm{CD} 45 \mathrm{RA}^{+}$ & $9.5 \pm 5.7$ & $13.1 \pm 8.1$ & 0.220 & $11(3-30)$ & $51.3(16-121)$ & $<0.001$ \\
\hline $\mathrm{CD}^{+} \mathrm{CD}^{2} 5 \mathrm{RO}^{+}$ & $13.8 \pm 7.7$ & $16.2 \pm 8.0$ & 0.647 & $16(5-39)$ & $63.6(16-150)$ & $<0.001$ \\
\hline $\mathrm{CD}^{+} \mathrm{CD}^{+}$ & $26.6 \pm 7.4$ & $27.9 \pm 9.2$ & 0.297 & $30(25-59)$ & $111.8(28-265)$ & $<0.001$ \\
\hline $\mathrm{CD}^{+} \mathrm{CD} 45 \mathrm{RA}^{+}$ & $19.6 \pm 6.6$ & $20.5 \pm 7.6$ & 0.625 & $22(11-60)$ & $79.0(20-189)$ & $<0.001$ \\
\hline $\mathrm{CD}^{+} / \mathrm{CD}^{+}$ & $1.04 \pm 0.5$ & $1.12 \pm 0.5$ & 0.967 & & & \\
\hline $\mathrm{CD}_{19}{ }^{+}$ & $12.3 \pm 5.0$ & $12.7 \pm 6.0$ & 0.659 & $14(5-42)$ & $48.5(12-90)$ & $<0.001$ \\
\hline $\mathrm{CD}^{-}{ }^{-} \mathrm{CD} 56^{+}$ & $10.0 \pm 7.0$ & $7.0 \pm 8.9$ & 0.144 & $12(6-38)$ & $27.9(3-76)$ & $<0.010$ \\
\hline Treg & $3.1 \pm 3.2$ & $2.3 \pm 2.0$ & 0.192 & $3.0(1.5-6.7)$ & $8.6(3.6-12.6)$ & $<0.010$ \\
\hline MDSCs & $0.66 \pm 0.23$ & $0.40 \pm 0.19$ & $<0.01$ & $3.9(1.4-7.3)$ & $3.5(1.7-6.0)$ & 0.045 \\
\hline
\end{tabular}

$\mathrm{CD}^{+}$cell and subsets, $\mathrm{CD} 19^{+}$cell, and $\mathrm{CD}^{-} \mathrm{CD}^{-} 6^{+}$cell frequencies are shown as percentage of the lymphocytes, $\mathrm{CD}^{+} \mathrm{CD}^{2} 5^{+} \mathrm{FOXP3}{ }^{+}$Treg frequencies are shown as percentage of $\mathrm{CD}^{+} \mathrm{CD}^{+}$cells, and MDSC frequencies are shown as percentage of total nucleated cells

\section{GVHD}

Six patients developed II-IV aGVHD in the G-BM group, 15 patients in the G-PBSC group. The cumulative incidence of II-IV aGVHD was $12.2 \% \pm 4.7 \%$ in the G-BM group compared to $28.8 \% \pm 6.3 \%$ in the G-PBSC group $(P=0.048)$, and III-IV aGVHD was $4.1 \% \pm 2.8 \%$ in the G-BM group compared to $9.6 \% \pm 4.1 \%$ in the G-PBSC group $(P=0.267)$. Ninety-five patients were alive at day +100 post-transplantation, cGVHD occurred in 10 patients in the G-BM group, and 20 patients in the G-PBSC group, including 4 cases and 8 cases persistent from aGVHD, respectively. The overall cumulative incidences of cGVHD at 3 years were $22.3 \% \pm 6.3 \%$ and $44.8 \% \pm 7.6 \% \quad(P=0.026)$, respectively, and extensive cGHVD were $4.5 \% \pm 3.1 \%$ and $15 \% \pm 5.3 \%(P=0.08)$, respectively, in G-BM and G-PBSC groups. Two patients died from cGVHD in G-PBSC group, while no patients died from cGVHD in G-BM group $(P>0.05)$. The comparison with historical data of 32 patients who underwent unstimulated $\mathrm{BM}$ transplantation in our institutions was also conducted. The results showed a trend of lower incidence of GVHD in G-BM comparing to that in unstimulated BM group (II-IV aGVHD, $12.2 \%$ vs $26.78 \%, P=0.070$; overall cGVHD $22.3 \%$ vs $37.5 \%$, $P=0.120$, respectively).

The impact of graft contents on the incidence of GVHD was further analyzed. The results showed that patients who developed no II-IV aGVHD received statistically higher numbers of MDSCs than patients who did (median, $3.73 \times 10^{6}$ cells $/ \mathrm{kg}$; range, 1.4 to $7.3 \mathrm{com}$ pared to $3.31 \times 10^{6}$ cells $/ \mathrm{kg}$; range, 1.5 to 5.8 , respectively, Fig. $3 \mathrm{a}, \quad P=0.034)$. Similarly, patients who developed no extensive cGVHD received significantly higher numbers of MDSCs comparing with patients who developed (median, $3.71 \times 10^{6}$ cells $/ \mathrm{kg}$; range, 1.4 to 7.3 compared to $2.7 \times 10^{6}$ cells $/ \mathrm{kg}$; range, 1.98 to 4.23 , respectively, Fig. $3 \mathrm{~b}, \quad P=0.016)$. Correlation analysis showed a significantly negative correlation between the numbers of MDSCs infused and the severity of aGVHD (Fig. 3c, $P=0.032, r=-0.214$ ). And a trend for negative correlation between MDSCs infusion and the severity of cGVHD was also found though without significant difference (Fig. 3d, $P=0.07, r=-0.181$ ).

While cell doses of other compositions including CD3 ${ }^{+} \mathrm{T}$ cells and Treg cells did not differ in patients developing acute or chronic GVHD or not (all $P>0.05$ ), similarly, no significant correlation was found between the numbers of other cellular components and acute or chronic GVHD (all $P>0.05$ ).

\section{Infections post-transplantation}

Within the first 100 days post-transplantation, 55 patients developed 86 episodes of bacterial and/or fungal infections. There were 12 and 10 cases of bacterial infections, 7 and 5 cases of fungal infections, and 10 and 11 cases of bacterial and fungal mixed infections, respectively, in GBM and G-PBSC groups (all $P>0.05$ ). One patient died from bacterial infection in G-BM group, while no patient died from infections in G-PBSC group $(P=1.000)$. Within 6 months post-transplantation, $14(28.6 \%)$ patients in GBM group and $16(30.8 \%)$ patients in G-PB group had CMV viremia $(P=0.808) ; 3$ patients in $\mathrm{G}-\mathrm{BM}$ group and 5 patients in G-PB group had EBV viremia $(P=1.000)$.

\section{Survival and relapse}

With a median follow-up of 701 days post-transplantation, 76 patients were alive. Eleven patients in the G-BM and 14 in the G-PBSC group died. Causes of death included 

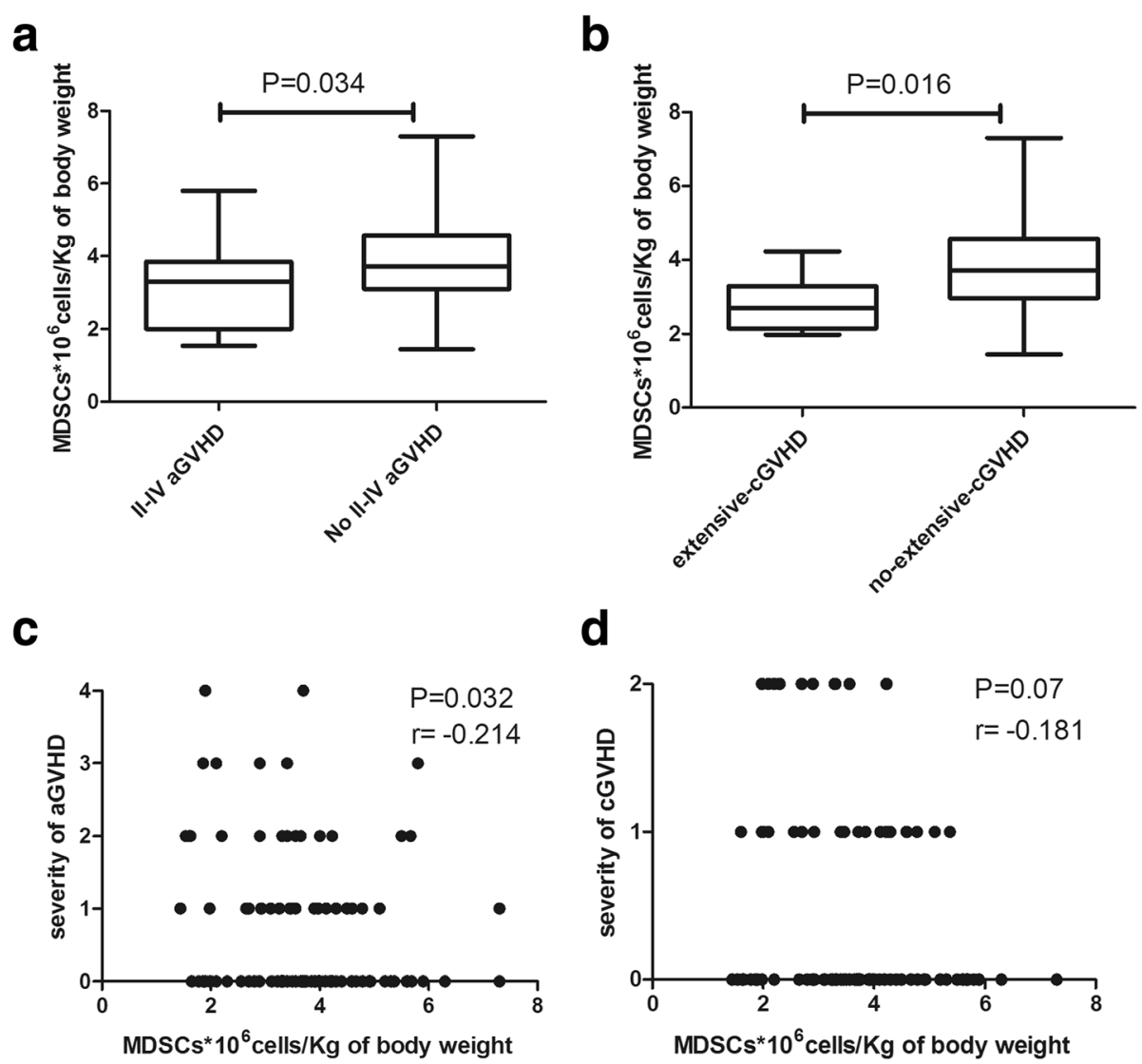

Fig. 3 Box plots showing the absolute number of infused MDSCs with respect to II-IV aGVHD (a) and extensive cGVHD (b). Bars represent the median values, whereas whiskers represent the minimum and maximum. The severity of aGVHD (c) and cGVHD (d) were plotted against the number of infused MDSCs. The grade for severity of CGVHD included limited and extensive CGVHD $(1=$ limited, $2=$ extensive, respectively). $r$ and $P$ values were calculated using Spearman's correlation test

leukemia relapse ( $n=7$ vs 8$)$, GVHD ( $n=1$ vs 3 ), and infections ( $n=3$ vs 3 ). Ten patients died of TRM, with 4 patients in G-BM group, and 6 patients in G-PBSC group $(P$ $=0.333)$. Nineteen patients experienced relapse, as a result of 9 in G-BM group and 10 in G-PBSC group. Of the 19 relapse patients, 3 patients abandoned treatment and the other 16 patients were treated with chemotherapy, donor lymphocyte infusion, or second allo-HSCT. Seven cases achieved CR after treatment.

The 3-year cumulative incidence of relapse was $18.9 \% \pm$ $5.8 \%$ and $19.6 \% \pm 5.7 \%$, respectively, in the G-BM and G-PBSC groups (Fig. 4a, $P=0.840$ ), and TRM were $8.2 \%$ $\pm 4.0 \%$ and $11.5 \% \pm 4.5 \%$, respectively, in the G-BM and G-PBSC groups (Fig. 4b, $P=0.549$ ). The 3 -year cumulative OS were $75.5 \% \pm 6.7 \%$ and $69.6 \% \pm 7.1 \%$, respectively, in the G-BM and G-PBSC groups (Fig. 4c, $P=0.426$ ), and DFS were $72.9 \% \pm 6.4 \%$ and $67.1 \% \pm 6.6 \%$, respectively, in the G-BM and G-PBSC groups (Fig. $4 \mathrm{~d}, P=0.456$ ). The G-BM group showed significantly higher probability of GRFS than the G-PBSC group $(73.5 \% \pm 6.3 \%$ vs $55.8 \% \pm$ $6.9 \%$ at 1 year, $P=0.049 ; 69.0 \% \pm 6.7 \%$ vs $49.7 \% \pm 7.0 \%$ at 2 and 3 years, $P=0.03$, respectively, Fig. 4e).
Risk factors for survival and relapse are presented in Table 3. In multivariate analysis, high risk of disease $(\mathrm{HR}=2.31$; $95 \%$ cumulative incidence $(95 \% \mathrm{CI}), 1.09-4.87$; $P=0.028)$ was associated with a lower DFS. MDSC cell dose below the median of $3.65 \times 10^{6}$ cells $/ \mathrm{kg}(\mathrm{HR}=3.49$; 95\% CI, 1.77-6.9; $P<0.001)$, older recipient age (HR = 2.02; 95\% CI, 1.07-3.8; $P=0.039$ ), and high risk of disease $(\mathrm{HR}=2.14 ; 95 \% \mathrm{CI}, 1.14-4.02 ; P=0.018)$ were significantly associated with a lower GRFS. All factors studied were not significantly associated with relapse or OS in the univariate and multivariate analyses (all $P>0.05$ ) (Table 3 ). Both $\mathrm{CD}^{+} \mathrm{T}$ cells and Treg cells did not influence the risk of relapse, OS, DFS, and GRFS. And no significant correlation between MDSC cell dose and relapse was found $(P>0.05)$, which indicated that higher content of MDSCs did not increase the incidence of relapse in this study.

\section{Discussion}

In the past two decades, unstimulated BM grafts have lost its use as the optimal source of HSCs because GPBSC grafts has faster hematopoietic reconstruction. However, G-PBSC grafts have its shortage of increased 

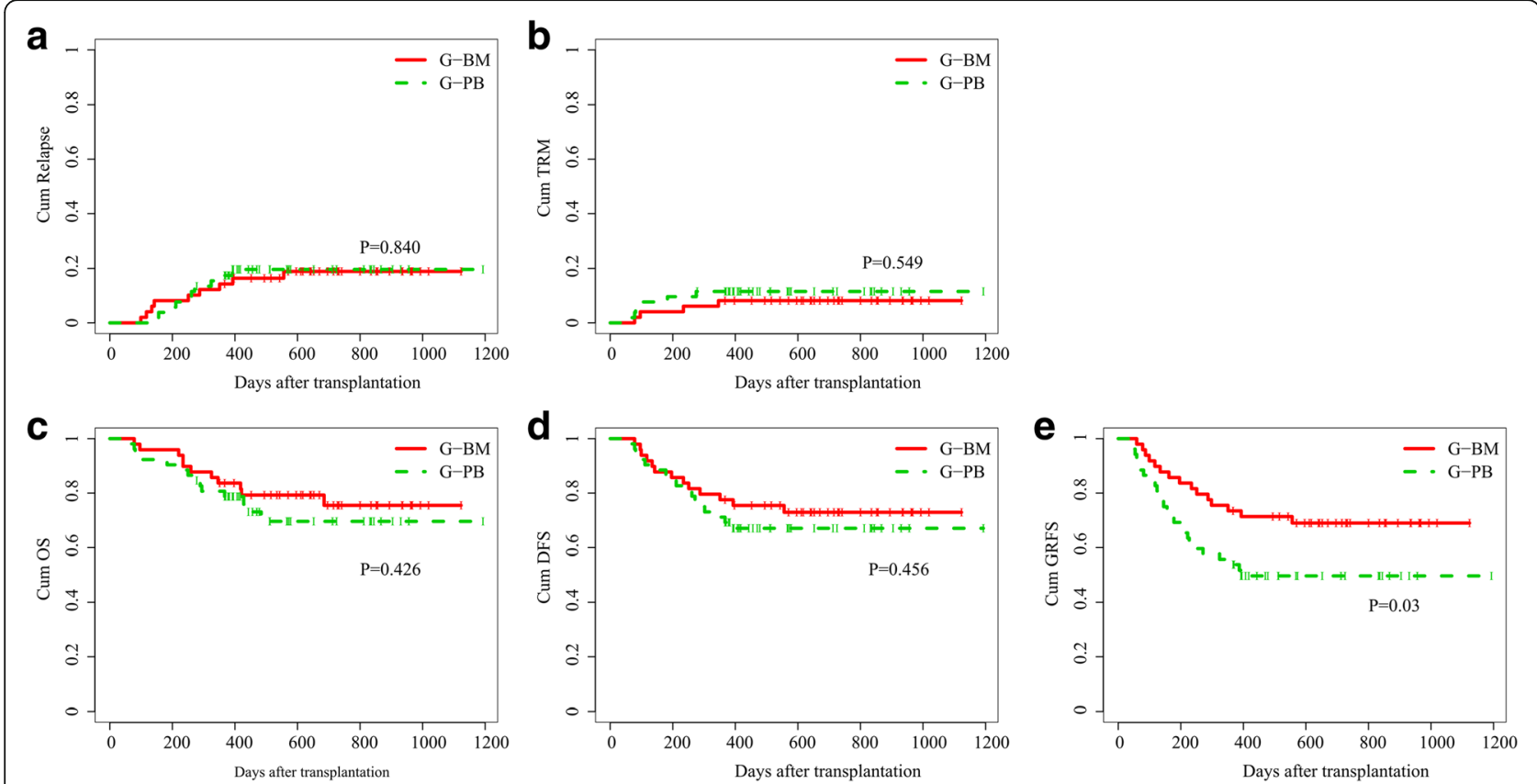

Fig. 4 Cumulative incidence of 3-year a relapse, b TRM, c OS, d DFS, and e GRFS. The 3-year cumulative incidence of relapse were 18.9\% $\pm 5.8 \%$ and $19.6 \% \pm 5.7 \%$ in G-BM and G-PBSC groups $(P=0.840)$, and TRM were $8.2 \% \pm 4.0 \%$ and $11.5 \% \pm 4.5 \%$, respectively, in G-BM and G-PBSC groups $(P=0.549)$. The 3 -year cumulative OS were $75.5 \% \pm 6.7 \%$ and $69.6 \% \pm 7.1 \%$, respectively, in the G-BM and G-PBSC group $(P=0.426)$, and DFS were $72.9 \% \pm 6.4 \%$ and $67.1 \% \pm 6.6 \%$, respectively, in the G-BM and G-PBSC groups ( $P=0.456)$. The 1 -year cumulative GRFS were $73.5 \% \pm 6.3 \%$ vs $55.8 \% \pm 6.9 \%$, respectively, in the G-BM and G-PBSC groups $(P=0.049)$, and 2 - and 3-year cumulative GRFS were $69.0 \% \pm 6.7 \%$ vs $49.7 \% \pm 7.0 \%$, respectively, in the G-BM and G-PBSC groups $(P=0.03)$

GVHD compared with unstimulated BM grafts. Recently, some studies suggested that G-BM grafts had similar hematopoietic reconstruction, and less cGVHD, compared with G-PBSC grafts. Serody et al. [24] and Morton et al. [25] reported that G-BM grafts showed significantly less cGVHD and aGVHD, respectively, and comparable engraftment to G-PBSC grafts. The recent investigation from a larger prospective randomized study showed that both the neutrophil and platelet recovery were statistical 3 days later, and G-BM grafts resulted in

Table 3 Univariate and multivariate analyses for relapse, OS, DFS, and GRFS

\begin{tabular}{|c|c|c|c|c|c|c|c|c|}
\hline \multirow[t]{2}{*}{ Risk factors } & \multicolumn{2}{|l|}{ Relapse } & \multicolumn{2}{|l|}{ OS } & \multicolumn{2}{|l|}{ DFS } & \multicolumn{2}{|l|}{ GRFS } \\
\hline & Univariate & $\begin{array}{l}\text { Multivariate } \\
(P(\mathrm{HR}, 95 \% \mathrm{Cl}))\end{array}$ & Univariate & $\begin{array}{l}\text { Multivariate } \\
(\mathrm{P}(\mathrm{HR}, 95 \% \mathrm{Cl}))\end{array}$ & Univariate & $\begin{array}{l}\text { Multivariate } \\
(P(\mathrm{HR}, 95 \% \mathrm{Cl}))\end{array}$ & Univariate & $\begin{array}{l}\text { Multivariate } \\
(P(\mathrm{HR}, 95 \% \mathrm{Cl}))\end{array}$ \\
\hline Female vs male & NS & NS & NS & NS & NS & NS & NS & NS \\
\hline Patient age, $\geq 33$ vs $<33$ years & NS & NS & NS & NS & NS & NS & NS & $\begin{array}{l}P=0.039 \\
(2.02,1.07-3.8)\end{array}$ \\
\hline ALL vs AML & NS & NS & NS & NS & NS & NS & NS & NS \\
\hline High risk vs standard risk & NS & NS & NS & NS & $P=0.03$ & $\begin{array}{l}P=0.028 \\
(2.31,1.09-4.87)\end{array}$ & NS & $\begin{array}{l}P=0.018 \\
(2.14,1.14-4.02)\end{array}$ \\
\hline G-PBSC vs G-BM & NS & NS & NS & NS & NS & NS & $P=0.03$ & $\begin{array}{l}P=0.071 \\
(1.82,0.95-3.49)\end{array}$ \\
\hline $\begin{array}{l}\mathrm{CD}^{+} \mathrm{T}, \geq 166 \times 10^{6} \mathrm{vs} \\
<166 \times 10^{6} \mathrm{cell} / \mathrm{sg}\end{array}$ & NS & NS & NS & NS & NS & NS & NS & NS \\
\hline $\begin{array}{l}\text { Treg, }<5.2 \times 10^{6} \mathrm{vs} \\
\geq 5.2 \times 10^{6} \text { cells } / \mathrm{kg}\end{array}$ & NS & NS & NS & NS & NS & NS & NS & NS \\
\hline $\begin{array}{l}\text { MDSCs, }<3.65 \times 10^{6} \text { vs } \\
\geq 3.65 \times 10^{6} \mathrm{cell} / \mathrm{sg}\end{array}$ & NS & NS & NS & NS & NS & NS & $P<0.001$ & $\begin{array}{l}P<0.001 \\
(3.49,1.77-6.90)\end{array}$ \\
\hline
\end{tabular}

OS overall survival, DFS disease-free survival, GRFS GVHD-free/relapse-free survival, $A L L$ acute lymphoblastic leukemia, $A M L$ acute myelogenous leukemia, TNC total nucleated cells 
a significantly lower cGVHD compared to G-PBSC grafts [26]. In this study, our results showed similar engraftment of neutrophil and platelet and a significantly lower cGVHD and aGVHD in G-BM group compared with that in G-PBSC group. Meanwhile, the presented study was compared with the historical data of patients who underwent unstimulated BM grafts in our institutions. The results showed that G-BM grafts had significantly faster engraftment in both neutrophil and platelet engraftment and a trend of lower acute and chronic GVHD compared with unstimulated BM grafts.

A variety of factors affect the incidence of GVHD, such as graft source, donor source, HLA compatibility, and GVHD prophylaxis [27-31]. Each graft source has its own components and show different immunological properties, which affect the incidence and severity of GVHD [10, 32, 33]. Though G-PBSC grafts contain 4- to 10-fold more $\mathrm{T}$ lymphocytes compared with un-BM grafts, the incidence and severity of aGVHD is surprisingly low and even comparable with that in unstimulated BM grafts [1], which is considered as a result of G-CSFinduced immune regulation.

G-CSF induces immune tolerance through a variety of mechanisms including modulation on graft contents $[34,35]$. MDSCs are a heterogeneous population with a potent immunosuppressive activity [11]. Recently, several experimental and clinical evidences suggested that MDSCs might play an immunoregulatory role in GVHD. Highfill et al. [13] demonstrated that adoptive transfer of MDSCs could inhibit the severity and mortality of GVHD. Vendramin et al. [14] reported that higher doses of monocytic MDSCs (M-MDSCs) in the G-PBSC grafts were associated with less aGVHD. Guan et al. [36] reported that the number of G-MDSCs in PB of patients at the preconditioning time point was negatively correlated with aGVHD. As the cellular effectors of aGVHD are mainly cytotoxic $\mathrm{T}$ lymphocytes and natural killer cells $[37,38]$, MDSCs are able to inhibit alloreactive responses mediated by $\mathrm{T}$ lymphocytes and NK cells through a variety of mechanisms, including L-arginine depletion by arginase 1 and the inducible nitric oxidase (iNOS), generation of reactive oxygen species, release of transforming growth factor-beta (TGF-beta) and IL-10, cysteine sequestration, and regulatory $\mathrm{T}$ (Treg) cell induction [11, 39-41]. In this study, our results were in line with the studies from Highfill et al. [13] and Vendramin et al. [14] showing that MDSC infusions were negatively correlated with incidence and severity of GVHD. Moreover, we found that G-BM grafts were associated with a significantly higher frequency of MDSCs, which might associate with its lower GVHD.

It is known that GVL effect mainly depends on T cell activity. So, we reasoned whether the higher MDSC content in the G-BM grafts increase the incidence of leukemia relapse because of its probable downregulated $\mathrm{T}$ cell responses. Animal models had demonstrated that the adoptive transfer of MDSCs can result in the successful control of GVHD without compromising GVT effects [13, 42]. In this study, the results revealed no significant difference in the relapse of G-BM and G-PBSC group and no significant correlation between the number of MDSCs infused and leukemia relapse. Similarly, Vendramin et al. [14] reported that the number of M-MDSCs infused did not correlate with tumor relapse. In addition, we also compared infections within the first 100 days post-transplantation, and the result showed no significant difference between the two groups, which might attribute to comparable engraftment with G-PBSC grafts. Meanwhile, it also indicated that higher MDSC content did not increase the infection rate.

GRFS is the primary endpoint of this research. Our results revealed that G-BM grafts showed significantly lower GVHD but similar hematopoietic reconstruction as well as relapse compared with G-PBSC grafts. So we questioned whether these results come to superior GRFS. As a result, the G-BM group showed significantly higher probability of 1-, 2-, and 3-year GRFS than the G-PBSC group. Considering the small sample size of this study, larger clinical trials need to be conducted as well as with further follow-up is wanted. In addition, BM grafts contain stromal cells such as mesenchymal stem cells (MSC), which show immunomodulatory effect on various immune cells. Whether stromal cells in G-BM grafts is associated with its lower GVHD compared with G-PBSC grafts need further research.

\section{Conclusions}

G-BM grafts lead a better GRFS and less GVHD associated with a higher MDSC content compared with G-PBSC grafts. And MDSCs might play the immunoregulatory role in GVHD.

\section{Abbreviations \\ 95\% Cl: 95\% cumulative incidence; ALL: Acute lymphoid leukemia; allo- HSCT: Allogeneic hematopoietic stem cell transplantation; AML: Acute myeloid leukemia; ANC: Absolute neutrophil count; BM: Bone marrow; Bu: Busulfan; CFSE: 5, 6-carboxy-fluorescein diacetate succinimidyl ester; CGVHD: Chronic graft-versus-host disease; CMV: Cytomegalovirus; CR1: First complete remission; Cy: Cyclophosphamide; DFS: Disease-free survival; EBV: Epstein-Barr virus; G-BM: Mobilized bone marrow; G-CSF: Granulocyte colony-stimulating factor; G-PBSC: Mobilized peripheral blood stem cells; GRFS: GVHD-free/relapse-free survival; GVHD: Graft-versus-host disease; GVL: Graft-versus-leukemia; HLA: Human leukocyte antigen; HR: Hazard ratio; HSCs: Hematopoietic stem cells; HVOD: Hepatic veno-occlusive disease; IFI: Invasive fungal infection; IMC: Immature myeloid cells; iNOS: Inducible nitric oxidase; MDSCs: Myeloid-derived suppressor cells; M-MDSCs: Monocytic myeloid-derived suppressor cells; NK: Natural killer; OS: Overall survival; PB: Peripheral blood; TBI: Total body irradiation; TGF-beta: Transforming growth factor-beta; Th2: T helper type 2; TNC: Total nucleated cells; TRM: Transplant- related mortality}




\section{Funding}

The study was supported by grants from National Natural Science Foundation of China (No. U1401221, 81470349, 81401315, 81500149), Science and Technology Planning Project of Guangdong Province (No. 2014B 020226004), and the Health Collaborative Innovation Major Projects of Guangzhou City (201400000003-4, 201508020254).

\section{Availability of data and materials}

All data generated or analyzed during this study are included in this published article (and its supplementary information files).

\section{Authors' contributions}

QF performed the investigations, analyzed the data, and wrote the paper; $\mathrm{HL}, \mathrm{XQL}, T Y, Z P F$, and FH analyzed the data; YWY, XL, LX, NX, XJX, and JYY performed the investigations; and QFL designed the study and wrote the paper. All authors read and approved the final manuscript.

\section{Ethics approval and consent to participate}

The study was approved by the respective Ethics Committee of Nanfang Hospital, the First People's Hospital of Chenzhou, People's Hospital of Zhongshan City, and Concord Hospital of the Fujian Medical University. Written informed consent was obtained from all the subjects in accordance with the Declaration of Helsinki.

\section{Consent for publication}

Not applicable.

\section{Competing interests}

The authors declare that they have no competing interests.

\section{Publisher's Note}

Springer Nature remains neutral with regard to jurisdictional claims in published maps and institutional affiliations.

\section{Author details}

'Department of Hematology, Nanfang Hospital, Southern Medical University, No. 1838 North Guangzhou Avenue, Guangzhou 510515, China. ${ }^{2}$ Department of Hematology, First People's Hospital of Chenzhou, No. 102 Luojiajing District, Chenzhou 423000, China. ${ }^{3}$ Department of Hematology, Concord Hospital of the Fujian Medical University, No. 29 Xinquan Road of Gulou District, Fuzhou 350001, China. ${ }^{4}$ Department of Hematology, People's Hospital of Zhongshan City, No. 2 Zhongshan Road, Zhongshan 528403, China.

Received: 26 April 2017 Accepted: 26 June 2017

Published online: 04 July 2017

\section{References}

1. Schmitz N, Dreger P, Suttorp M, Rohwedder EB, Haferlach T, Loffler H, Hunter A, Russell NH. Primary transplantation of allogeneic peripheral blood progenitor cells mobilized by filgrastim (granulocyte colony-stimulating factor). Blood. 1995;85(6):1666-72

2. Majolino I, Saglio G, Scime R, Serra A, Cavallaro AM, Fiandaca T, Vasta S, Pampinella M, Catania P, Indovina A, et al. High incidence of chronic GVHD after primary allogeneic peripheral blood stem cell transplantation in patients with hematologic malignancies. Bone Marrow Transplant. 1996; 17(4):555-60.

3. Moraleda J, Baileng A, Sierra J. Chronic graft-versus-host disease after allogeneic peripheral blood progenitor cell or bone marrow transplantation from matched related. Bone Marrow Transplant. 1998;22:1129-35.

4. Deotare U, Al-Dawsari G, Couban S, Lipton JH. G-CSF-primed bone marrow as a source of stem cells for allografting: revisiting the concept. Bone Marrow Transplant. 2015;50(9):1150-6.

5. Pan L, Delmonte JJ, Jalonen CK, Ferrara J. Pretreatment of donor mice with granulocyte colony-stimulating factor polarizes donor T lymphocytes toward type-2 cytokine production and reduces severity of experimental graft-versus-host disease. Blood. 1995;86(12):4422-9.

6. Sloand EM, Kim S, Maciejewski JP, Van Rhee F, Chaudhuri A, Barrett J, Young NS. Pharmacologic doses of granulocyte colony-stimulating factor affect cytokine production by lymphocytes in vitro and in vivo. Blood. 2000;95(7):2269-74
7. Klangsinsirikul P, Russell NH. Peripheral blood stem cell harvests from G-CSF-stimulated donors contain a skewed Th2 CD4 phenotype and a predominance of type 2 dendritic cells. Exp Hematol. 2002;30(5):495-501.

8. Chen SH, Li X, Huang XJ. Effect of recombinant human granulocyte colonystimulating factor on T-lymphocyte function and the mechanism of this effect. Int J Hematol. 2004;79(2):178-84.

9. Przepiorka D, Smith TL, Folloder J, Khouri I, Ueno NT, Mehra R, Korbling M, Huh YO, Giralt S, Gajewski J, et al. Risk factors for acute graft-versus-host disease after allogeneic blood stem cell transplantation. Blood. 1999; 94(4):1465-70.

10. Chaidos A, Patterson S, Szydlo R, Chaudhry MS, Dazzi F, Kanfer E, McDonald D, Marin D, Milojkovic D, Pavlu J, et al. Graft invariant natural killer T-cell dose predicts risk of acute graft-versus-host disease in allogeneic hematopoietic stem cell transplantation. Blood. 2012;119(21):5030-6.

11. Gabrilovich DI, Nagaraj S. Myeloid-derived suppressor cells as regulators of the immune system. Nat Rev Immunol. 2009;9(3):162-74.

12. Ramachandran IR, Martner A, Pisklakova A, Condamine T, Chase T, Vogl T, Roth J, Gabrilovich D, Nefedova Y. Myeloid-derived suppressor cells regulate growth of multiple myeloma by inhibiting T cells in bone marrow. J Immunol. 2013;190(7):3815-23.

13. Highfill SL, Rodriquez PC, Zhou Q, Goetz CA, Koehn BH, Veenstra R, Taylor PA, Panoskaltsis-Mortari A, Serody JS, Munn DH, et al. Bone marrow myeloid-derived suppressor cells (MDSCs) inhibit graft-versus-host disease (GVHD) via an arginase-1-dependent mechanism that is up-regulated by interleukin-13. Blood. 2010;116(25):5738-47.

14. Vendramin A, Gimondi S, Bermema A, Longoni P, Rizzitano S, Corradini P, Carniti C. Graft monocytic myeloid-derived suppressor cell content predicts the risk of acute graft-versus-host disease after allogeneic transplantation of granulocyte colony-stimulating factor-mobilized peripheral blood stem cells. Biol Blood Marrow Transplant. 2014;20(12):2049-55.

15. Ling YW, Liu QF, Liu C, Wu XL, Chen YK, Fan ZP, Xuan L, Zhang Y, Jiang QL, Zhao J. [Effect of granulocyte colony stimulating factor on myeloid-derived suppressor cells in the bone marrow and peripheral blood: a preliminary study]. Nan Fang Yi Ke Da Xue Xue Bao. 2011;31(7):1190-2.

16. Xuan L, Huang F, Fan Z, Zhou H, Zhang X, Yu G, Zhang Y, Liu C, Sun J, Liu Q. Effects of intensified conditioning on Epstein-Barr virus and cytomegalovirus infections in allogeneic hematopoietic stem cell transplantation for hematological malignancies. J Hematol Oncol. 2012;5:46.

17. Ruggeri A, Labopin M, Ciceri F, Mohty M, Nagler A. Definition of GvHD-free, relapse-free survival for registry-based studies: an ALWP-EBMT analysis on patients with AML in remission. Bone Marrow Transplant. 2016;51(4):610.

18. Holtan SG, DeFor TE, Lazaryan A, Bejanyan N, Arora M, Brunstein CG, Blazar BR, MacMillan ML, Weisdorf DJ. Composite end point of graft-versus-host disease-free, relapse-free survival after allogeneic hematopoietic cell transplantation. Blood. 2015;125(8):1333-8.

19. Przepiorka D, Weisdorf D, Martin P, Klingemann H, Beatty P, Hows J, Thomas E. 1994 consensus conference on acute GVHD grading. Bone Marrow Transplant. 1995;15(6):825-8.

20. Horwitz ME, Sullivan KM. Chronic graft-versus-host disease. Blood Rev. 2006;20(1):15-27.

21. Gooley TA, Leisenring W, Crowley J, Storer BE. Estimation of failure probabilities in the presence of competing risks: new representations of old estimators. Stat Med. 1999;18(6):695-706.

22. Gray RJ. A class of K-sample tests for comparing the cumulative incidence of a competing risk. Ann Stat. 1988;16(3):1141-54.

23. Fine JP, Gray RJ. A proportional hazards model for the subdistribution of a competing risk. J Am Stat Assoc. 1999;94(446):496-509.

24. Serody JS, Sparks SD, Lin Y, Capel EJ, Bigelow SH, Kirby SL, Gabriel DA, Wiley JM, Brecher ME, Schell MJ, et al. Comparison of granulocyte colonystimulating factor (G-CSF)-mobilized peripheral blood progenitor cells and G-CSF-stimulated bone marrow as a source of stem cells in HLA-matched sibling transplantation. Biol Blood Marrow Transplant. 2000;6(4A):434-40.

25. Morton J, Hutchins C, Durrant S. Granulocyte-colony-stimulating factor (G-CSF)primed allogeneic bone marrow: significantly less graft-versus-host disease and comparable engraftment to G-CSF-mobilized peripheral blood stem cells. Blood. 2001;98(12):3186-91.

26. Couban S, Aljurf M, Lachance S, Walker I, Toze C, Rubinger M, Lipton JH, Lee SJ, Szer J, Doocey R. Filgrastim-stimulated bone marrow compared to filgrastimmobilized peripheral blood in myeloablative sibling allografting for patients with hematologic malignancies: a randomized Canadian blood and marrow transplant group study. Biol Blood Marrow Transplant. 2016;22(8):1410-5. 
27. Lu D-P, Dong L, Wu T, Huang X-J, Zhang M-J, Han W, Chen H, Liu D-H, Gao Z-Y, Chen Y-H. Conditioning including antithymocyte globulin followed by unmanipulated HLA-mismatched/haploidentical blood and marrow transplantation can achieve comparable outcomes with HLA-identical sibling transplantation. Blood. 2006;107(8):3065-73.

28. Gao L, Zhang C, Gao L, Liu Y, Su Y, Wang S, Li B, Yang T, Yuan Z, Zhang X. Favorable outcome of haploidentical hematopoietic stem cell transplantation in Philadelphia chromosome-positive acute lymphoblastic leukemia: a multicenter study in Southwest China. J Hematol Oncol. 2015;8:90.

29. Chang YJ, Zhao XY, Xu LP, Zhang XH, Wang Y, Han W, Chen H, Wang FR, Mo XD, Zhang YY, et al. Donor-specific anti-human leukocyte antigen antibodies were associated with primary graft failure after unmanipulated haploidentical blood and marrow transplantation: a prospective study with randomly assigned training and validation sets. J Hematol Oncol. 2015;8:84.

30. Ruggeri A, Battipaglia G, Labopin M, Ehninger G, Beelen D, Tischer J, Ganser A, Schwerdtfeger R, Glass B, Finke J, et al. Unrelated donor versus matched sibling donor in adults with acute myeloid leukemia in first relapse: an ALWP-EBMT study. J Hematol Oncol. 2016;9(1):89.

31. Rubio MT, Savani BN, Labopin M, Polge E, Niederwieser D, Ganser A, Schwerdtfeger R, Ehninger G, Finke J, Renate A, et al. The impact of HLA-matching on reduced intensity conditioning regimen unrelated donor allogeneic stem cell transplantation for acute myeloid leukemia in patients above 50 years - a report from the EBMT acute leukemia working party. J Hematol Oncol. 2016;9(1):65.

32. Eapen M, Rocha V, Sanz G, Scaradavou A, Zhang MJ, Arcese W, Sirvent A, Champlin RE, Chao N, Gee AP, et al. Effect of graft source on unrelated donor haemopoietic stem-cell transplantation in adults with acute leukaemia: a retrospective analysis. Lancet Oncol. 2010;11(7):653-60.

33. Eapen M, Le Rademacher J, Antin JH, Champlin RE, Carreras J, Fay J, Passweg JR, Tolar J, Horowitz MM, Marsh JC, et al. Effect of stem cell source on outcomes after unrelated donor transplantation in severe aplastic anemia. Blood. 2011;118(9):2618-21.

34. Rutella S, Zavala F, Danese S, Kared H, Leone G. Granulocyte colony-stimulating factor: a novel mediator of T cell tolerance. J Immunol. 2005;175(11):7085-91.

35. Zeng D, Dejbakhsh-Jones S, Strober S. Granulocyte colony-stimulating factor reduces the capacity of blood mononuclear cells to induce graft-versushost disease: impact on blood progenitor cell transplantation. Blood. 1997; 90(1):453-63.

36. Guan Q, Blankstein AR, Anjos K, Synova O, Tulloch M, Giftakis A, Yang B, Lambert P, Peng Z, Cuvelier GD. Functional myeloid-derived suppressor cell subsets recover rapidly after allogeneic hematopoietic stem/progenitor cell transplantation. Biol Blood Marrow Transplant. 2015;21(7):1205-14.

37. Hill GR, Ferrara JL. The primacy of the gastrointestinal tract as a target organ of acute graft-versus-host disease: rationale for the use of cytokine shields in allogeneic bone marrow transplantation. Blood. 2000;95(9):2754-9.

38. Herrero-Sanchez MC, Rodriguez-Serrano C, Almeida J, San Segundo L, Inoges S, Santos-Briz A, Garcia-Brinon J, Corchete LA, San Miguel JF, Del Canizo C, et al. Targeting of PI3K AKT/mTOR pathway to inhibit T cell activation and prevent graft-versus-host disease development. J Hematol Oncol. 2016;9(1):113.

39. Zea AH, Rodriguez PC, Atkins MB, Hernandez C, Signoretti S, Zabaleta J, McDermott D, Quiceno D, Youmans A, O'Neill A, et al. Arginase-producing myeloid suppressor cells in renal cell carcinoma patients: a mechanism of tumor evasion. Cancer Res. 2005;65(8):3044-8.

40. Filipazzi P, Valenti R, Huber V, Pilla L, Canese P, lero M, Castelli C, Mariani L, Parmiani G, Rivoltini L. Identification of a new subset of myeloid suppressor cells in peripheral blood of melanoma patients with modulation by a granulocyte-macrophage colony-stimulation factor-based antitumor vaccine. J Clin Oncol. 2007;25(18):2546-53.

41. Hoechst B, Ormandy LA, Ballmaier M, Lehner F, Kruger C, Manns MP, Greten TF, Korangy F. A new population of myeloid-derived suppressor cells in hepatocellular carcinoma patients induces CD4(+)CD25(+)Foxp3(+) T cells. Gastroenterology. 2008;135(1):234-43.

42. Macdonald KP, Rowe V, Clouston AD, Welply JK, Kuns RD, Ferrara JL, Thomas R, Hill GR. Cytokine expanded myeloid precursors function as regulatory antigen-presenting cells and promote tolerance through IL-10-producing regulatory T cells. J Immunol. 2004;174(4):1841-50.

\section{Submit your next manuscript to BioMed Central and we will help you at every step:}

- We accept pre-submission inquiries

- Our selector tool helps you to find the most relevant journal

- We provide round the clock customer support

- Convenient online submission

- Thorough peer review

- Inclusion in PubMed and all major indexing services

- Maximum visibility for your research

Submit your manuscript at www.biomedcentral.com/submit 